\title{
Congenital double chambered left ventricle treated by exclusion of accessory chamber
}

\author{
P H KAY, M RIGBY, H C MULHOLLAND \\ From the Brompton Hospital, London; and the Department of Paediatric Cardiology, Royal Belfast Hospital for Sick \\ Children
}

SUMMARY A 9 month old boy with a double chambered left ventricle presented with congestive cardiac failure refractory to medical treatment. He was successfully treated by surgical exclusion of the accessory chamber.

The double chambered left ventricle is a rare condition and to our knowledge only six cases have been previously reported ${ }^{1-4}$ We present the first case of this condition successfully treated by exclusion of the accessory chamber.

\section{Case report}

This child was born at 38 weeks gestation after a normal pregnancy. His birthweight was $3.2 \mathrm{~kg}$.

He remained well until the age of 3 months when he started to experience feeding difficulties, and at the age of 4 months he was admitted to the Royal Belfast Hospital for Sick Children in congestive cardiac failure. This was treated with digoxin $0.03 \mathrm{mg} \mathrm{bd}$, frusemide $10 \mathrm{mg}$ bd, and aldactone $6.25 \mathrm{mg}$ bd. Cardiac catheterisation at this time showed a double chambered left ventricle (Fig 1). There was free communication between the two chambers, both of which contracted poorly. The pressures in the two chambers were identical $(90 / 10 \mathrm{mmHg})$. In view of persistent failure to thrive he was referred to the Brompton Hospital, London, for surgical management.

Examination of the chest showed a prominent cardiac impulse at the left sternal border. The heart sounds were normal, with a grade $2 / 4$ ejection systolic murmur in the fourth left intercostal space. The rest of the physical examination was normal.

Chest $x$-ray film disclosed gross cardiomegaly (cardiothoracic ratio $16 / 20$ ), with prominent pulmonary vascular markings. Electrocardiogram showed sinus rhythm with a mean $Q R S$ frontal axis of +30 , left ventricular hypertrophy, and $T$ wave inversion in leads V5 and V6. Cross-sectional echocardiography showed situs solitus, atrioventricular concordance, and ventriculoarterial concordance. A large accessory chamber appeared to be arising from the lateral border of the left ventricle. The ejection fraction was calculated at $26 \%$.

\section{OPERATIVE DETAILS}

Surgery was performed under deep hypothermia and circulatory arrest. The child was surface cooled to $23^{\circ} \mathrm{C}$ when the chest was opened via a median sternotomy incision. The left ventricle was observed to be contracting poorly. There was no external evidence of a discrete diverticulum or aneurysm. Cardiopulmonary bypass was established between a single right atrial cannula and the ascending aorta. The patient was then further cooled to a nasopharyngeal temperature of $15^{\circ} \mathrm{C}$ and the circulation stopped. A vertical incision was made at the apex of the left ventricle between the left anterior descending coronary artery and its third diagonal branch (Fig. 2a). The "accessory chamber" was entered and its wall appeared to contain viable myocardium. The chamber communicated freely with the main left ventricular chamber (Fig. 2b) through a large fibrous orifice $(2.5 \mathrm{~cm} \times 2$ $\mathrm{cm})$. Using a series of vertical buttressed 4/0 Prolene mattress sutures the fibrous orifice was approximated to the wall of the accessory chamber excluding the accessory chamber while preserving its functional myocardium (Fig. $2 c$ and $2 d$ ). The ventriculotomy was then closed with two layers of continuous $4 / 0$ Prolene (Fig. 2e). The postoperative course was uneventful. He was discharged on the tenth day taking frusemide $4 \mathrm{mg}$ bd and spironolactone $8 \mathrm{mg}$ bd.

Endomyocardial biopsy showed muscular hypertrophy with irregularly arranged fibroelastic tissue distinct from the regular palisades typical of endomyocardial fibroelastosis. 


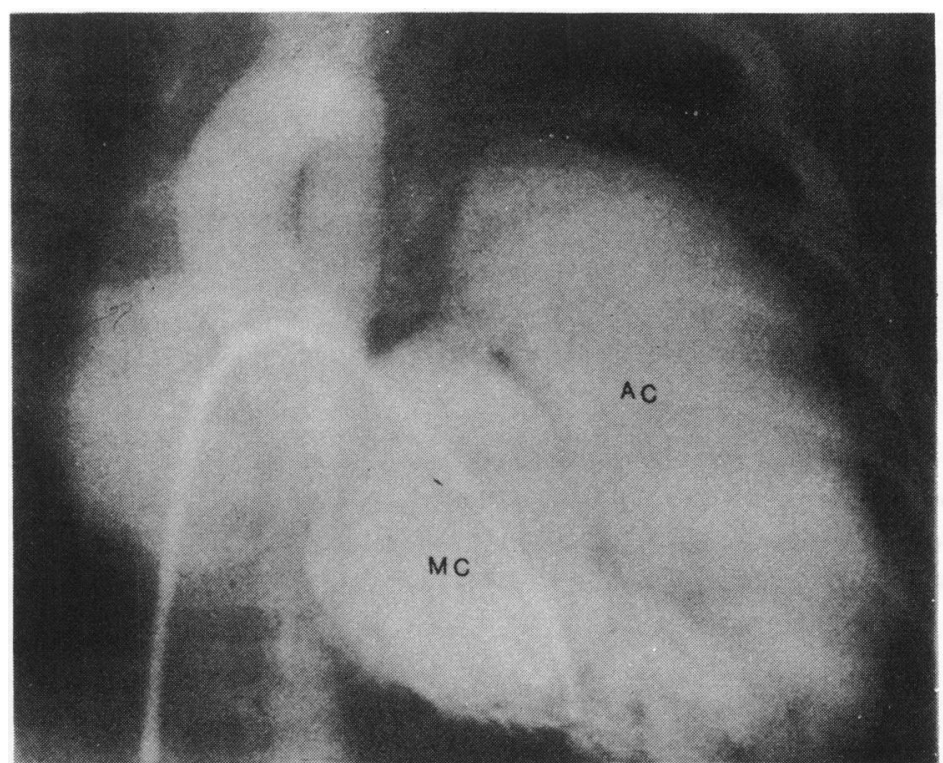

Fig. 1 Left ventriculogram showing the double-chambered left ventricle. MC, main left ventricular chamber; $A C$, accessory chamber.

\section{FOLLOW UP}

The child was reviewed at the age of 15 months, six months after operation. He appeared a healthy active child who was walking. His weight had increased to $11 \mathrm{~kg}$ (50th centile for weight). Examination of the precordium disclosed a normal cardiac impulse. The heart sounds were normal and there was no residual murmur. Chest $x$-ray film showed that the heart was still enlarged though the cardiothoracic ratio had reduced to $12 / 20$. The electrocardiogram was unchanged. The left ventricular ejection fraction, calculated from repeat cross-sectional echocardiography, had risen to $44 \%$

\section{Discussion}

Double chambered right ventricle, itself a rare condition, is created by one or more muscle bundles traversing the right ventricle. ${ }^{56}$ It is typically associated with a ventricular septal defect, and indeed the picture may be confused when the rudimentary chamber connects with the left ventricle resulting in double left ventricular chamber haemodynamics. ${ }^{7}$ Our case, however, was one of true double chambered left ventricle, the accessory chamber lying anterolateral to the main chamber, with the left anterior descending coronary artery and its diagonal branches running across the surface.

The aetiology of the double-chambered left ventricle is obscure, but appears to be related to a cardiomyopathy. The two early descriptions by
Paronetto and Strauss ${ }^{3}$ and Ruttenberg et al. 4 ca reported "aneurysms" secondary to congenital car-̄̄ diomyopahy. Gerlis et al..$^{2}$ suggested that endocardialö fibroelastosis rendered the main chamber non- $\varrho$ contractile and that the functional portion of the left $\vec{O}$ ventricle was derived from intramyocardial sinusoids. 3 The histology in this report was similar to the cases of cardiomyopathy reported by Alday et al. ${ }^{1}$

The indication for surgery in this case was failure to thrive. The choice of operation was determined in theon operating theatre, when the anatomical and patholog-? ical appearances were clearly visible. Resection of the accessory chamber was inappropriate as it would haveo involved excision of a large amount of viable myocar- dium including the left anterior descending coronaryo artery. Patch closure of the "ostium" between the two chambers would have resulted in too small a volumeo in the left ventricular cavity. Thus, a plastic procedure was chosen to maintain the orifice between theor chambers widely open while obliterating the "deadN space" of the accessory chamber.

There is little information on the natural history of the double chambered left ventricle. Five of the previous cases reported died, while a long term follow up on the sixth patient, treated medically, is lacking. Inc? this particular case the operation appeared to produce a dramatic result, assessed both subjectively by theo mother and objectively in the form of normal gain in weight, decrease in cardiothoracic ratio on the chesto radiograph, and increase in left ventricular ejection
fraction. 
Congenital double chambered left ventricle treated by exclusion of accessory chamber
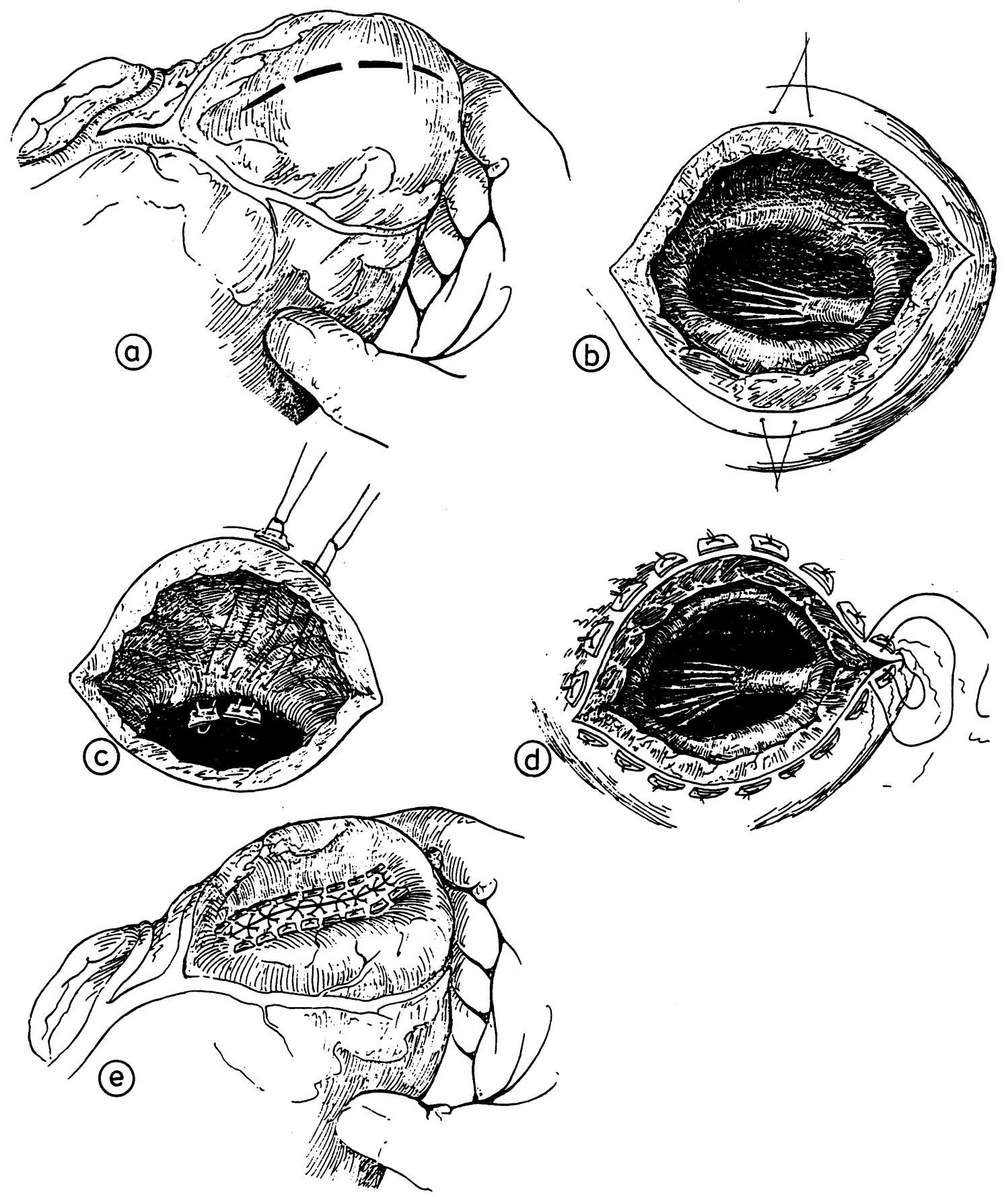

Fig. 2 (a) Vertical incision in the left ventricle between the left anterior descending coronary artery and its third diagonal branch. (b) Accessory chamber with ostivm leading into true left ventricle. (c) Buttressed vertical mattress sutures inserted through the fibrous orifice and the free wall of the accessory chamber. (d) Accessory chamber excluded. (e) Lefi ventriculotomy closed. 
The authors would like to thank Mr J C R Lincoln for permission to report this case.

\section{References}

1 Alday LE, Moreyra E, Quiroga C, Buonano C, Dander B. Cardiomyopathy complicated by left ventricular aneurysms in children. Br Heart $\mathcal{F}$ 1976; 38: 162-6.

2 Gerlis LM, Partridge JB, Fiddler GI, Williams G, Scott $O$. Two-chambered left ventricle. Three new varieties. Br Heart F 1981; 46: 278-84.

3 Paronetto F, Strauss L. Aneurysm of the left ventricle due to congenital muscle defect in an infant. Am $\mathcal{f}$ Cardiol 1963; 12: 721-9.

4 Ruttenberg HD, Jue KL, Elliott LP, Anderson RC,

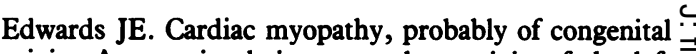
origin. A case simulating anomalous origin of the left coronary artery from the pulmonary trunk. Circulation 1964; 29: 768-76.

5 Hartmann AF Jr, Goldring D, Ferguson TB, et al. The course of children with the two-chambered right ventricle. F Thorac Cardiovasc Surg 1970; 60: 72-83.

6 Rowland TW, Rosenthal A, Castaneda AR. Double- in chamber right ventricle: experience with 17 cases. $\mathrm{Am}$ Heart f 1975; 89: 455-62.

7 Beitzke A, Anderson RH, Wilkinson JL, Shinebourne EA. Two-chambered right ventricle: simulating twochambered left ventricle. $\mathrm{Br}$ Heart $\mathcal{F}$ 1979; 42: 22-6.

Requests for reprints to Mr P H Kay, FRCS, London ị Chest Hospital, Bonner Road, London E2 9JX. 